\title{
Fatal outcome following gastric endoscopic sub- mucosal dissection in a patient with liver cirrhosis
}

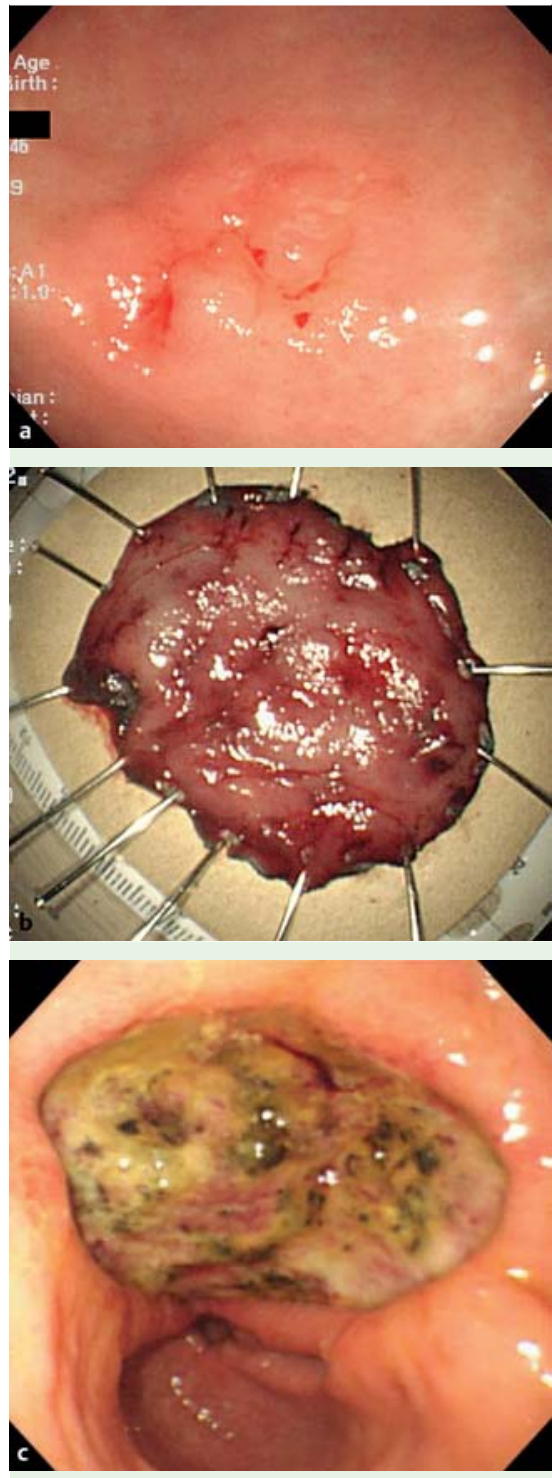

Fig. 1 Early gastric cancer and endoscopic submucosal dissection (ESD). a Endoscopic image shows an elevated mucosal lesion $2 \mathrm{~cm}$ in size with a central depression, situated at the lesser curvature of the mid antrum. $\mathbf{b}$ The specimen, completely resected en bloc and fixed by pins. c An artificial ulcer crater is seen without evidence of perforation on day 1 after the ESD procedure.

A 73-year-old woman was admitted to hospital for management of early gastric cancer. Esophagogastroduodenoscopy (EGD) demonstrated a 2-cm elevated mucosal lesion with a central depression on the lesser curvature of the distal antrum, which after forceps biopsy was confirmed

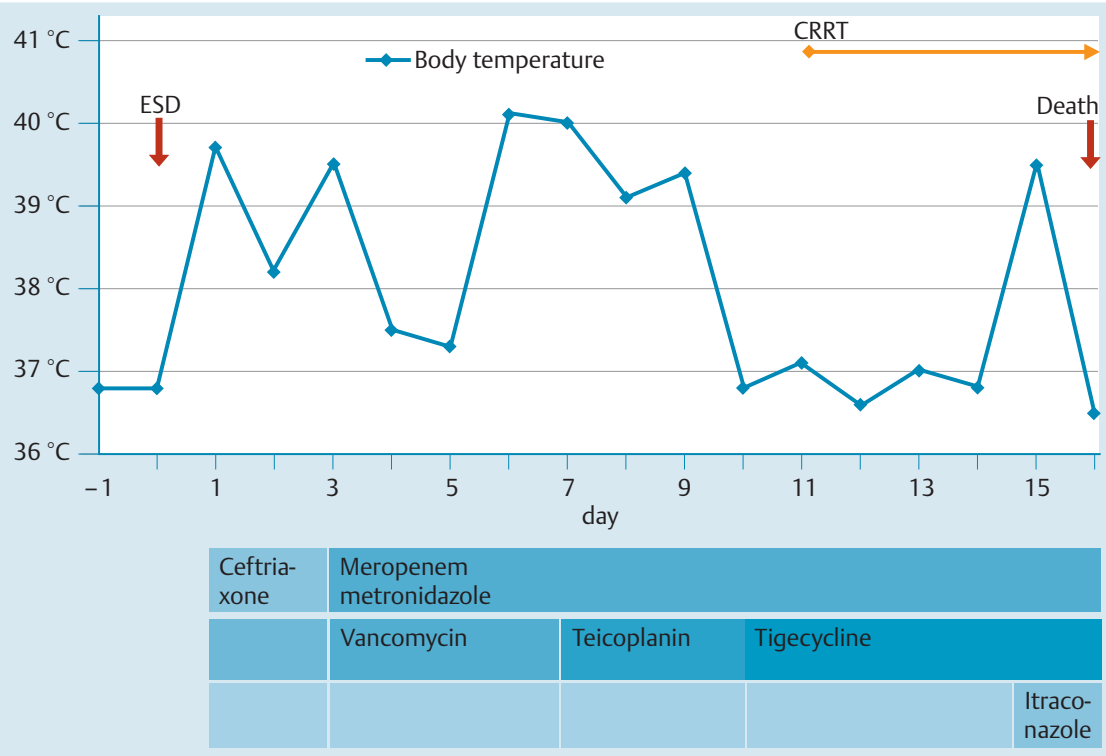

Fig. 2 Fever pattern and clinical course of the patient after endoscopic submucosal dissection. ESD, endoscopic submucosal dissection; CRRT, continuous renal replacement treatment.

histopathologically to be a well-differentiated adenocarcinoma ( $\bullet$ Fig. 1 ). The patient's medical history was significant for liver cirrhosis related to hepatitis $C$ virus, hypertension, and type 2 diabetes mellitus. She had been monitored for 3 years for Child-Pugh class A liver cirrhosis. Her vital signs were stable. Her laboratory test results were as follows: white blood cell count $2.2 \times 10^{9} / \mathrm{L}$, hemoglobin $9.1 \mathrm{~g} / \mathrm{L}$, platelet count $62 \times 10^{9} / \mathrm{L}$, creatinine $0.8 \mathrm{mg} /$ $\mathrm{dL}$, albumin $3.2 \mathrm{~g} / \mathrm{dL}$, aspartate aminotransferase $90 \mathrm{U} / \mathrm{L}$, alanine aminotransferase $54 \mathrm{U} / \mathrm{L}$, and glucose $129 \mathrm{mg} / \mathrm{dL}$. Abdominal computed tomography (CT) confirmed the presence of liver cirrhosis with splenomegaly. An endoscopic submucosal dissection (ESD) was performed using propofol and midazolam for balanced sedation. The lesion was successfully removed in 85 minutes and no adverse event occurred. The tumor was confined within the muscularis mucosa without lymphovascular involvement and the resection margins were clear.

The patient complained of fever and chills (body temperature $39^{\circ} \mathrm{C}$ ) 11 hours after the ESD. The fever persisted despite empirical treatment with a third-generation cephalosporin. Chest and abdominal CT, echocardiography, and follow-up EGD failed to find a cause of the fever. We switched antibiotics to meropenem. On the 10th postoperative day, the patient's bilirubin and liver enzyme concentrations started to rise and oliguria developed. The results of the third blood culture identified Klebsiella pneumoniae sensitive to current antibiotics. However, the patient's clinical condition worsened and she died of progressive liver failure on the 16th day after ESD ( $\bullet$ Fig. 2).

Although the exact cause of the death of this patient is not clear, we speculate that a hidden infection via bacteremia might be the explanation for her deterioration. The incidence of transient bacteremia after gastric ESD is between $2 \%$ and $4 \%$ $[1,2]$.

No previous report of mortality related to gastric ESD exists, and we have reported elsewhere that gastric ESD can be safely performed on patients with liver cirrhosis [3]. However, the present case makes us reconsider the safety of ESD for patients with liver cirrhosis. Endoscopists should consider that ESD may possibly be accompanied by unexpected complications and may change the course of the disease even if the resection itself is successful. 
Endoscopy_UCTN_Code_CPL_1AH_2AZ

Competing interests: None

H. Y. Lee, E. S. Kim, Y. J. Lee, Y. J. Ha, K. B. Cho, K. S. Park

Department of Internal Medicine, Keimyung University School of Medicine, Daegu, Korea

\section{References}

1 Kato $M$, Kaise $M$, Obata $T$ et al. Bacteremia and endotoxemia after endoscopic submucosal dissection for gastric neoplasia: pilot study. Gastric Cancer 2012; 15: 15-20

2 Itaba S, Iboshi $Y$, Nakamura $K$ et al. Low frequency of bacteremia after endoscopic submucosal dissection of the stomach. Dig Endosc 2011; 23: 69-72

3 Kwon YL, Kim ES, Lee KI et al. Endoscopic treatments of gastric mucosal lesions are not riskier in patients with chronic renal failure or liver cirrhosis. Surg Endosc 2011; 25: 1994-1999

\section{Bibliography}

DOI http://dx.doi.org/

10.1055/s-0032-1325858

Endoscopy 2012; 44: E431-E432

(c) Georg Thieme Verlag KG

Stuttgart · New York

ISSN 0013-726X

\section{Corresponding author}

\section{E. S. Kim, MD}

Department of Internal Medicine and Division of Gastroenterology and Hepatology Keimyung University School of Medicine 194 Dong San-dong

Jung-gu

Daegu 700-712

South Korea

Fax: +82-53-2507088

dandy813@hanmail.net 